\title{
Deriving the Order of Heads and Adjuncts: The Case of Niuean DPs
}

\author{
Arsalan Kahnemuyipour and Diane Massam \\ Syracuse University/University of Toronto
}

\section{Introduction}

This paper examines substantive noun phrases in Niuean, a Polynesian language of the Tongic subgroup with VSO word order, isolating morphology, and an ergative case system. We describe the allowable orderings of elements in the Niuean noun phrase, which include certain variations in the placement of numerals and the genitive possessor, then we provide a phrasal movement analysis for these variations, treating first the possessor variation, then the numeral variation. Parallels will be drawn between the derivation of nominal and sentential word order.

There has been a large quantity of work, both recent and traditional, attempting to understand why certain orders of elements in clauses seem to be universally ruled out. To account for this, some linguists have posited that there is a universal order of elements and that allowable variations on this order are derived by various movement patterns (e.g. Cinque 1996, 1999, 2000, 2002, Belleti 2004, Rizzi 1997, 2003). This position allows for the theory to rule out ungrammatical orders by universal constraints on movement, rather than by typological stipulations. Our exploration of the Niuean DP takes place in light of this type of work, as well as similar work specifically on DPs such as den Dikken 2003, Pearce 2002, 2003. and Shlonsky 2004. Given that Niuean DPs have a Ninitial order, similarly to the V-initial order of clauses, our analysis also addresses the relation between nominal structure and sentential structure, finding striking parallels between the two clause-types. We confirm a movement constraint observed by Rackowski and Travis (2000), which states that purely relational functional projections such as Agreement, which have no semantic content, are invisible to certain types of movement.

\section{Description of the Niuean DP}

The Niuean DP is described in Seiter (1980), and in Massam and Sperlich (2000). In a DP without a possessor or numeral, the order of elements is as shown in (1) below. First, there is a portmanteau morpheme, which indicates the case of the DP as well as whether it is common or proper (where proper includes pronominal). In (1a,b) this particle is $e$ (absolutive common), whereas in (1e) it is $a$ (absolutive proper). (Ergative common DPs begin with the particle he, and ergative proper DPs begin with $e$.) This is followed by an optional marker for number, which also has classifier-like properties, as can be seen in (1a) and (1b) where a different plural marker appears depending on the nature of the noun or group. Other plural classifiers include lafu for a family group, atu for a row, and na: for a pair. (For a discussion of the relation between classifiers and number markers, see Fassi Fehri 
and Vinet, 2004). This marker can also have article-like properties, in that an indefinite plural NP can appear with falu (a), as in (1c) and in the case of a singular indefinite NP, the marker taha or ha can appear in this position, as in (1d). We will refer to this complex morpheme simply as number (\#) in this paper. This morpheme is followed by the head noun, which is in turn optionally followed by one or more adjectives as in (1a) and a demonstrative as in (1a). (1e) shows a proper DP. The order of elements in the DP is fixed.

(1) Order of Elements without Possessors and Numerals

( $\mathrm{C}=$ common $\mathrm{P}=$ proper/pronoun, Colon indicates a long vowel)

\begin{tabular}{|c|c|c|c|c|}
\hline Case+P/C & \# & Noun & Adjs & Dem \\
\hline
\end{tabular}

a. e tau manu kula fulufuluola e:

AbsC Pl bird red beautiful Dem

'those beautiful red birds' (Field Notes.01)

b. e kau kaiha

AbsC group thieves

'a group of thieves' (Seiter 1980.100a)

c. e falu (a) tagata

AbsC some person

'some people' (Sperlich 1997.67)

d. e taha tagata

AbsC one person

'a person' (Field Notes.01)

e. a Moka

AbsP Moka

'Moka' (Field Notes.97)

In DPs with possessors, the situation is a little more complex. (Examples with numerals will be discussed further below.) There are two possible orders, as shown in (2). The first order finds the genitive case marked possessor in prenominal position. In this order, there is a ligature item $a$ appearing between the possessor and the noun, as in (2a). The second order finds the genitive marked possessor at the end of the entire DP (after the demonstrative if there is one), as in $(2 b)$.

(2) Orders of Elements with Possessors

\begin{tabular}{lllllll} 
a. Case $+\mathrm{P} / \mathrm{C}$ & Poss $a$ & $\#$ & Noun & Adjs & Dem & \\
b. Case+P/C & & $\#$ & Noun & Adjs & Dem & Poss \\
\hline
\end{tabular}




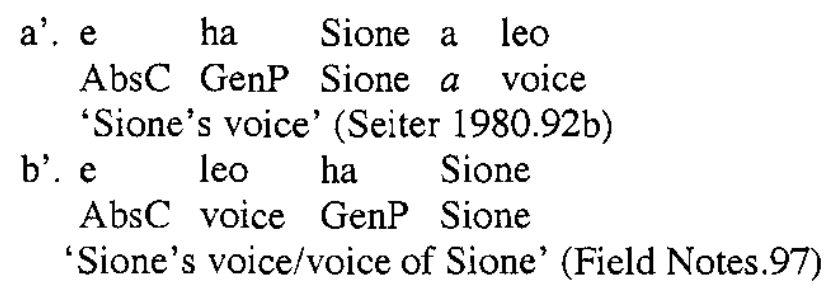

The pre-nominal possessive construction has two particular properties distinct from the properties of the construction with the possessor at the end of the clause. First, the pre-nominal possessor gives a definiteness reading to the DP as a whole, similarly to the situation in Hebrew and Arabic (see, e.g. Ritter 1988, Shlonsky 1988, Borer 1999), as shown in (3). (3a) has a definite reading, whereas (3b), like non-possessed Niuean DPs, can be definite or indefinite.

(3) a. ko e haana a fale

Pred his a house

'It's his house.' [definite] (Sperlich 1997.103)

b. ko e fale haana

Pred house his

'It's his house/a house of his' (Sperlich 1997.103)

The second property of the pre-nominal possessor construction is that the pre-nominal possessor must be proper as in (2a), or pronominal as in (3a). It is ungrammatical to have a common pre-nominal possessor, although such a possessor is fine in final position, as shown in $(4 a, b)$.

(4) a. Ko e pepa he faiaoga

Pred AbsC book GenC teacher

'the book of the teacher' (Field Notes.01)

b. *Ko e he faiaoga a pepa

Pred AbsC GenC teacher a book

('the teacher's book') (Field Notes.01)

Given the facts described above, we will address the following two questions: How do we derive the order of elements? How do we account for the two positions (and corresponding properties) of the possessor?

\section{Setting the stage}

Let us first address the question of the order of elements. One logical possibility is to assume that $\mathrm{N}$ is base-generated in the same place it surfaces in (2a), i.e. between the \# and the Adjectives. Given the impossibility of $\mathrm{N}$ taking Adjectives and Demonstratives as complements, the only way to have this option is to assume a combination of right and left branching, contra Kayne's (1994) antisymmetric system, which disallows left branching universally. Note that this would violate even a weaker version of an antisymmetric system, which would 
allow cross-linguistic variation in branching direction, but not different directions of branching within a single language or within a single phrasal category. We thus take $\mathrm{N}$ in (2a) to be base-generated at the end of the phrase, as shown in (5) (where all other elements appear in their surface order), and we derive its surface position, and those of the other elements, in a manner to be elaborated below.

(5) $\mathrm{Case}+\mathrm{P} / \mathrm{C} \quad \#$ Adjs Dem N

One way of deriving the order in (2a) is to allow $\mathrm{N}$ to move over Dem and Adjs to the medial position. We do not adopt this option for two reasons. First, if this is an instance of head-movement, it violates the Head Movement Constraint. If taken to be XP-movement, some constraint on the movement would be required. Otherwise, it would have to be stipulated that this element moves between \# and Adjs, and not, for instance, between Case and \# or Adjs and Dem, etc. More importantly, linguists who assume a basic universal order and have constraints on movement to account for the order of elements, account for some typological generalizations that would be hard to capture if we allowed this type of movement.

Let us look at some of these typological facts and see how they are accounted for by assuming a universal order of elements. The usual order of elements in the Noun Phrase was perhaps first observed by Greenberg (1966). His observation is given in (6).

(6) Universal 20 (Greenberg 1966:111, see also Hawkins 1983)

"When any or all of the items - demonstrative, numeral, and descriptive adjective - precede the noun, they are always found in that order. If they follow, the order is either the same or its exact opposite."

The generalization in (6) is partially summarized in (7). We leave aside numerals for the moment.

(7) Cinque (1996) and subsequent work, see also Kayne (1994)
a. $\operatorname{Dem}-\mathrm{A}-\mathrm{N}$
$=$ Base Ordering
b. ${ }^{*} \mathrm{~A}-\mathrm{Dem}-\mathrm{N}$
$=$ Impossible
c. $N-$ Dem $-A$
=Noun Movement
d. $\mathrm{N}-\mathrm{A}-\mathrm{Dem}$
$=$ Successive $\mathrm{XP}$ raising
$\rightarrow$ Niuean

Cinque (1996) accounts for the ordering restrictions in (7) in the following manner. (7a) is the basic order. The order in (7c) is the result of N-movement (later revised to remnant movement, which we leave aside here). Finally, the mirror-image order in (7d) is the result of successive XP-movement, which we suggest is what happens in Niuean. Crucially, if the XP-movement is successive and local, (7b) is impossible. Our approach is different in technical details from that of Cinque, but the idea is the same. One technical difference, for instance, is that Cinque places the pre-nominal modifiers in Specifier positions, whereas we consider them to be Heads. Our analysis is in line with Rackowski and Travis 
(2000) in these respects. See also Shlonsky (2004), who considers that some elements are heads, while others are in specifier position.

Another related fact is the order of descriptive adjectives. It has been suggested that there is a universal order of descriptive adjectives (Laenzlinger 2000, Scott 1998, Sproat \& Shih 1991), given in (8).

\section{Proposed Universal Order of Adjectives}

\section{Quantification $>$ Quality $>$ Size $>$ Shape $>$ Color $>$ Nationality}

If in a language like Niuean there is successive XP-movement to derive the mirror-image order, one would expect the adjectives to appear in reverse order as well. This prediction is borne out in all the examples we found in texts. We saw an example of this in (1a) with 'color' and 'quality' in the opposite order. The same phenomenon is observed in (9a) for 'color' and 'size' and in (9b) for 'size' and $o t i$ 'all', which we take to be a quantificational adjective.

(9) a. e letio kula tote

AbsC radio red little

'the little red radio' (Nelisi 1995.6)

b. e tau koloa ikiiki oti ia haaku...

AbsC Pl store small(Pl) all Dem my

'all those small stores of mine' (de Sousa 2001.50)

In the next section, we discuss the details of how the inverse order is derived in Niuean.

\section{Deriving inverse order}

The base order we assume for functional heads is given in (10). This order is based on a body of work on functional categories within the noun phrase. (For examples, see, Ghomeshi and Ritter 1996, Megerdoomian 2002, Pearce 2002, Phan 2001, Ritter 1991, 1995, Schoorlemmer 1998, Travis 1992, among others).

(10) Basic DP Order

$$
\begin{array}{|lllllll}
\hline K & \mathrm{D} & \text { Poss } & \text { Dem } & \text { A } & \# & \text { N } \\
\hline
\end{array}
$$

The order of $\mathrm{K}$ and $\mathrm{D}$ in (10) follows standard assumptions in generative theory (see; for K, Bittner and Hale 1996 and for D, Abney 1987). Note that D is null in Niuean.

With respect to the Poss head, it has been suggested in the literature that there are two positions across languages, one lower position much closer to the noun, which is utilized, for instance, by Semitic languages and one higher one, which we suggest is the one used in Niuean. (English possibly uses both positions, e.g. 'John's damaged car door.') Schoorlemmer (1998) discusses these 
two possibilities and the properties she attributes to the languages that use the high position coincide with properties of Niuean. We will return to this point below.

For Dem and $A$, we are following Cinque as in (7). For Number (\#), we are following Ritter (1991, 1992).

The order (2a) is derived in a manner illustrated in (11) which involves successive 'intraposition' or roll-up movement of the complements to their empty specifiers. As shown in (11), the \#P moves to the spec of AP, then the whole AP moves to the spec of DemP, DemP cannot move to the already filled spec of PossP and finally PossP moves to the spec of DP. DP, with an empty head (see below), does not move, hence $\mathrm{K}$ (not represented in (11)), appears at the far left.

(11) Pre-nominal possessor derivation (2a)

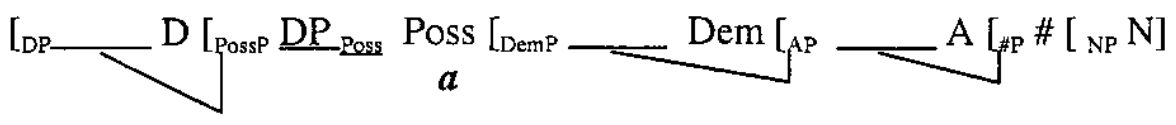

The question arises as to why NP does not move to the specifier of \#P. This can be answered easily if \# is in specifier position of \#P, in which case it would block the movement of NP. This claim is supported by the fact falu usually appears with an optional particle $a$, which is arguably the head of \#P, and by the fact that taha has an alternative form $h a$, suggesting that this number marker is formed of two parts, with $t a$ in specifier and $h a$ in head position.

The pre-nominal order of the possessor has two properties given below.

Property 1: Pre-nominal possessor gives a definiteness reading to the DP as a whole (3a).

According to Schoorlemmer (1998), in languages with the high PossP, Poss is a potential carrier of a value for definiteness. We posit that $a$ in Niuean is one such element. The Poss head, which is home to $a$, an element with semantic content, gives the whole DP the definite reading.

Property 2: The pre-nominal possessor must be proper or pronominal (2a, 3a).

We posit that the Poss morpheme $a$ has a [proper] feature which must be shared with its specifier. This is supported by the fact that $a$ has three other uses in Niuean that bear the feature proper (Absolutive proper case, proper article in goal DPs and Genitive proper case). Thus, $a$ has two roles, giving the definite reading to the whole DP and the [proper] feature to the possessor.

Let us now turn to the order (2b). This is shown in (12). 


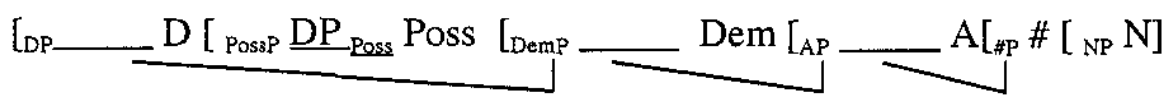

The first two movements are exactly the same as (11), \#P to spec of AP and AP to spec of DemP. The only difference here is that there is no $a$ in Poss. To get the right order, we need the whole DemP to move over PossP to the spec of DP, as shown in (12). The question remains, however, as to why in (12) DemP, rather than PossP, moves to spec of DP. Recall that in (11), it was PossP that moved, which is expected under some version of relativized minimality or shortest move. To explain the phenomenon in (12), we make use of an idea in Rackowski and Travis (2000), where they derive the order of adverbs in Malagasy and Niuean from Cinque's universal order of adverbs. Let us look at their analysis briefly.

Their derivation for the Niuean verb phrase is given in (13).

(13) Niuean clausal derivation (adapted from Rackowski \& Travis 2000)

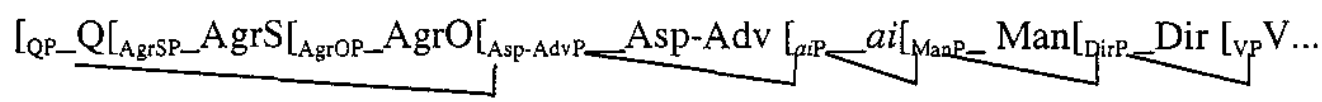

Note the striking parallel between (13) and (12), which essentially involve the same series of movements. Thus, in (13), VP moves to spec of DirP, DirP to spec of ManP, and so forth. Crucially, when the movement sequence gets to the $\mathrm{AgrO}$ and AgrS phrases, they are skipped and they cannot themselves move. To account for this fact, Rackowski and Travis suggest a restriction on movement given in (14).

(14) Rackowski \& Travis (2000:127)

"To avoid this ungrammatical derivation, there must be a restriction in the grammar such that non-contentful phrases like AgrP are invisible to movement and cannot themselves move. In contrast to this, contentful phrases like AdvPs can and, in this case must, move."

The restriction is that non-contentful phrases like AgrP are invisible to movement and cannot themselves move. We suggest that the same restriction is in place for PossP in (13). Note the plausibility of this suggestion, given the parallel between AgrP and PossP. In fact, we seem to have come across a striking example to support their proposal. Here, we have a head, which is contentful in one case and non-contentful in the other. When it is non-contentful as in (12), it is skipped and cannot itself move. In (11), on the other hand, the Poss head is contentful; it contains the feature definite realized by $a$. In this case, as predicted by Rackowski and Travis, the PossP moves which results in the pre-nominal possessor order. (See den Dikken (to appear) for a different approach to word order and to linking items.) 


\section{Numerals}

As well as variation in word order of possessors, Niuean exhibits variation in word order of numerals. Given what we have proposed for Niuean, we expect an inverse order for numerals compared with adjectives and demonstratives: [Adjective - Numeral - Demonstrative], as outlined in (6) from Greenberg (1966) and also discussed in Cinque (1996). Let us consider how numerals actually do behave in Niuean.

In fact, in Niuean, numerals are found both preceding and following the noun, as shown in (15). When numerals precede the noun, a ligature item $e$ appears between the numeral and the noun, similarly to pre-nominal possessors. It is preferred that the number marker be null in such cases. In case of post-nominal numerals, this ligature item does not appear. (Note when counting humans, the prefix toko appears on the numeral, which is sometimes written as part of the numeral, or with a hyphen, and sometimes written as a separate word as in the examples.)

(15) a.toko-lima e tagata loloa

Pers-five Ligperson tall

'five tall people' (de Sousa 2001.33)

b. Maori toko ua

Maori Pers three

'three Maoris' (Blanc and Togakilo 1965)

Pre-nominal numerals can co-occur with possessors. The most commonly found construction with both a numeral and a possessor is one where the numeral precedes the noun and the possessor follows it, as in (16).

(16) Ko e toko fa: e tama a Matakuhifi

Pred AbsC Pers four Ligboy Gen Matakuhifi

'Matakuhifi's four sons' (Blanc and Togakilo 1965)

Let us consider first the pre-nominal numeral order in (15a) and (16). If we take the base order to be that assumed by Cinque (1996), namely [Dem Numeral Adj N], the order in (15a) and (16) can be derived in a straightforward manner. (The examples here, however, do not include a demonstrative or \# marker.)

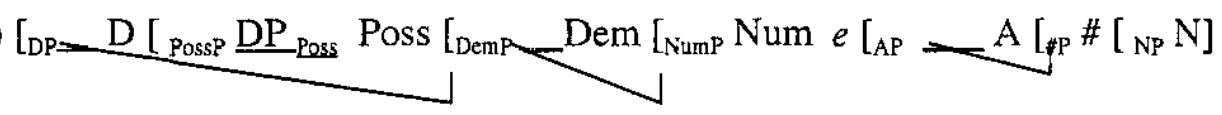

First, the \#P moves to the specifier of AP, just as in all the derivations so far. At this point, it is not possible to move the AP into the specifier of NumP, because this position is filled by the Numeral, while the head of NumP is filled by the particle $e$. Instead, the NumP is moved to the specifier of DemP. This 
movement exactly parallels the movement in (11) of PossP to DP, in place of movement of DemP to PossP, the latter of which is similarly blocked by a full specifier position. Then, the derivation proceeds as does that in (12), to yield the order in (15a) and (16) where the numeral is pre-nominal. This derivation yields a post-nominal possessor and a pre-nominal numeral as in (16).

In Niuean, each of the possessor and the numeral can appear prenominally $(2 \mathrm{a} \& 15 \mathrm{a})$. It is unclear whether both the possessor and the numeral can be pre-nominal in the same phrase, because there is a strong tendency on the part of speakers to avoid having more than one such element on one or other side of the noun. We leave this question open, pending future fieldwork.

Let us now address the post-nominal numerals, as in (15b). Note that there is no ligature item $e$ in these cases. Our analysis of nominal movements laid out in this paper might predict that in such a situation, NumP will resist movement, as PossP did in (12) to yield a word order [Poss \# N A Dem Num], which is not what is found, since numerals do not appear after demonstratives in Niuean.

(18) An Incorrect Prediction

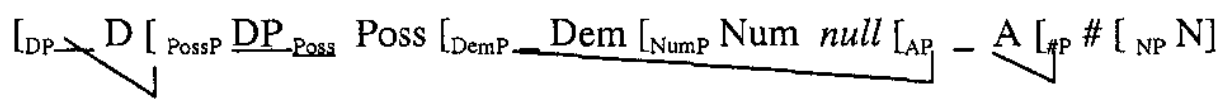

A solution lies in the analysis of numerals as heads in such cases (see Shlonsky 2003). If this position is tenable, the correct derivation results.

(19)

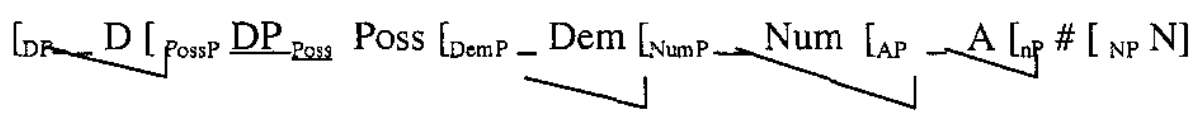

This derivation yields the word order [Poss \# N A Num Dem]. The important question is, does Niuean conform to the Greenberg generalization that when post-nominal, numerals follow adjectives? It is difficult to determine this, because, as just discussed, there is a strong preference to avoid having strings of multiple 'modifiers' (in the loose sense, including numerals and possessors). Thus, when a noun is modified by both a possessor or adjective and a numeral, one or other of them is usually found pre-nominally, while the remaining one is found post-nominally. This is true of all natural examples we have found in texts, as (16). When the data was elicited, in fact, varying orders were accepted when presented, as shown in (20).
a. e tau manu ua kula fulufuluola e:
AbsC Pl bird three red beautiful Dem
'those three beautiful red birds' (Field Notes 2001)
b. e tau manu kula ua fulufuluola e:
AbsC Pl bird red three beautiful Dem
'those three beautiful red birds' (Field Notes 2001) 
The status of such orders remains unclear, however, given the lack of such examples in Niuean texts. We note here simply that it is possible to derive these varying orders by choices regarding piedpiping, but since the status of these examples seems marginal, we do not discuss them further here.

In addition to the uses above, Niuean numerals can also function as predicates as in (21). In this function, they often modify noun phrases within a relative clause, as in (22). This serves as another strategy to avoid pile-up of modifiers in the noun phrase, and is common when there are multiple modifiers, as in (22), and (23) from de Sousa (2002).

(21) Valu e hui he feke

eight AbsC leg Gen octopus

'An octopus has eight legs.' (Sperlich 1997)

(22) motu ikiiki moe tokolalo ne fa:

island small and sandy Comp four

'four small and sandy islets' ((lit. 'small and sandy islets that are four')

(Blanc and Togakilo 1965)

(23) fiamanako au ke sela e tau koloa ikiki oti ia haku

want I Comp sell AbsC PI store small all Dem my

ne lima $i$ Niue ne mai e Sione

Comp five Loc Niue Comp give Erg:P Sione

'I want to sell all those five small shops of mine in Niue which I have inherited from Sione.' (de Sousa 2001.50)

Examples such as (22) and (23), with a relative clause, and examples with a PP argument, as in (23), along with deverbal nominal clauses raise further questions about word order in Niuean nominal phrases, however these questions remain for future research.

\section{Conclusion}

Following Cinque (2000), we have presented a roll-up analysis of Niuean DPs that derives the correct word orders and accounts for the position and properties of possessors, and for the variation in pre-nominal and post-nominal numerals. Having a filled specifier can affect the pattern of movement (Shlonsky 2004), and in addition, we have claimed, following Rackowski and Travis (2000), that the stoppage of movement that is seen in some cases in Niuean is tied to the content of functional heads. If the head is filled, movement of the phrase is possible, but if the head is phonologically and semantically empty, the phrase does not move. In the case of numerals we posited that when the ligature morpheme is absent, the numeral itself is in the head position. 
ACKNOWLEDGEMENTS: We would like to thank Ofania lkiua and Harry and Manamana for their work as Niuean consultants, and audiences of the U. of T, syntax group, of CLA, and of AFLA for useful comments and discussion. Funding for this work has been provided by SSHRCC grant "Issues in Niuean Syntax" \#410-01-1415.

\section{References}

Abney, Steven. 1987. The English Noun Phrase in its Sentential Aspect. Doctoral dissertation, MIT.

Belleti, Adriana. (ed.) 2004. Structures and Beyond - The Cartography of Syntactic Structures. Vol 3. Oxford: Oxford University Press.

Bittner, Maria and Ken Hale. 1996. The Structural Determination of Case and Agreement. Linguistic Inquiry, 27, 1-68.

Blanc, R. R. V. and Togakilo (translator). 1965. Ne Toka Hifo e Kuki e Higoa Haana he Tau Aelani. Islands Education Division, Dept. of Education, Wellington, New Zealand.

Borer, Hagit. 1999. Deconstructing the Construct. in Kyle Johnson and Ian Roberts (eds.) Beyond Principles and Parameters. Kluwer Publishing:.Dordrecht. pp.43-89.

Cinque, Guglielmo. 1996. The Antisymmetric Programme: Theoretical and Typological Implications. Journal of Linguistics, 32, 447-464.

Cinque, Guglielmo. 1999. Adverbs and Functional Heads: A Cross-linguistic Perspective. Oxford: Oxford University Press.

Cinque, Guglielmo. 2000. On Greenberg's Universal 20 and the Semitic DP. The University of Venice Working Papers in Linguistics, 10.2, 45-61.

Cinque, Guglielmo, (ed.) 2002. The functional structure of DP and IP - The Cartography of Syntactic Structures. Vol.1. Oxford: Oxford University Press.

den Dikken, Marcel. 2003. The Structure of the Noun Phrase in Rotuman. LINCOM Studies in Austronesian Linguistics 05, München, Germany.

den Dikken Marcel. To appear. Relators and Linkers: The Syntax of Predication, Predicate Inversion and Copulas. Cambridge: MIT Press.

Fassi Fehri, Abdelkader and Marie-Thérèse Vinet. To appear. Distribution of Number and Classifier in Arabic and Chinese and Parameterization. Linguistic Research 9.1. IERA Publications. Rabat.

Ghomeshi, Jila, and Elizabeth Ritter. 1992. Binding, Possessives, and the Structure of DP. Proceedings of NELS 26, K. Kusumoto (ed), GLSA, University of Massachusetts.

Greenberg, Joseph. 1966. Language Universals: With Special Reference to Feature Hierarchies. The Hague: Mouton.

Hawkins, John A. 1983. Word Order Universals. New York: Academic Press.

Kayne, Richard. 1994. The Antisymmetry of Syntax. Cambridge: MIT Press.

Laenzlinger, Christopher. 2000. French Adjective Ordering: Perspectives on DPinternal Movement Types. Generative Grammar in Geneva 1, 55-104. 
Massam, Diane and Wolfgang Sperlich. 2000. Possession in Niuean. in Steven Fischer (ed.) Possessive Markers in Central Pacific Languages. Thematic volume of Language Typology and Universals, 53.3/4, 281-292.

Megerdoomian, Karine. 2002. Beyond Words and Phrases: A Unified Theory of Predicate Composition. Doctoral dissertation. University of Southern California.

Nelisi, Lino. 1995. Ko e Letio Kula. Wellington: Ministry of Education.

Pearce, Elizabeth. 2002. DP Structure and DP Movement in Maori. Paper presented at COOL5, University of Canberra, Australia.

Pearce, Elizabeth. 2003. Phrasal movement within the Maori DP. Digests of Selected Papers Presented at AFLA X. University of Hawai'i at Manoa Working Papers in Linguistics 34.2. Pp. 41-42.

Phan, Kristin. 2001. Not so Bare after all: Observations on the Cantonese Nominal Phrase. ms. University of Toronto.

Rackowski, Andrea and Lisa Travis. 2000. V-initial Languages: X or XP Movement and Adverb Placement. in Andrew Carnie and Eithne Guilfoyle (eds.) The Syntax of Verb Initial Languages. Oxford: Oxford University Press.

Ritter, Elizabeth. 1988. A Head Movement Approach to Construct-State Noun Phrases. Linguistics, 26, 909-929.

Ritter, Elizabeth. 1991. Two Functional Categories in Noun Phrases: Evidence from Modern Hebrew. in Susan. D. Rothstein (ed.) Perspectives on Phrase Structure: Heads and Licensing. Syntax and Semantics 25. New York: Academic Press. 37-62.

Ritter, Elizabeth. 1993. Where's Gender? Linguistic Inquiry: 24.4: 795-803.

Rizzi, Luigi. 1997. The Fine Structure of the Left Periphery, in Liliane Haegeman (ed.) Elements of Grammar. Dordrecht: Kluwer Publishing.

Rizzi, Luigi. (ed.) 2003. The Structure of CP and IP - The Cartography of Syntactic Structures. Vol. 2. Oxford: Oxford University Press.

Schoorlemmer, Maaike. 1998. Possessors, Articles and Definiteness. in Artemis Alexiadou and Chris Wilder (eds.) Possessors, Predicates and Movement in the Determiner Phrase. Amsterdam: Benjamins.

Scott, G.-J. 1998. Stacked Adjectival Modification and the Structure of Nominal Phrases. SOAS Working Papers in Linguistics and Phonetics, Vol. 8, 5989.

Seiter, William. 1980. Studies in Niuean Syntax. New York: Garland Press.

Shlonsky, Ur. 1988. Government and Binding in Hebrew Nominals. Linguistics, 26, 951-976.

Shlonsky, Ur. 2004. The Form of Semitic Noun Phrases. Lingua 114.12: 14651526.

de Sousa, Hilario. 2001. Noun Phrase Structure and the Case Marking System in Niuean. ms. University of Auckland.

Sperlich, Wolfgang. 1997. Tohi Vagahau Niue/Niue Language Dictionary. Honolulu and Alofi: University of Hawai'i Press and the Government of Niue. 
Sproat, Richard \& Chilin Shih. 1991. The Cross-linguistic Distribution of Adjective Ordering Restrictions. in Carol Georgopolous \& R. Ishihara (eds.) Interdisciplinary Approaches to Language. Essays in Honor of $S$. $Y$. Kuroda. Dordrecht: Kluwer Publishing.

Travis, Lisa. 1992. Inner Tense with NP: the Position of Number. CLA Proceedings. University of Toronto Working Papers in Linguistics. pp. 329-346.

Arsalan Kahnemuyipour

Syracuse University

Department of Languages, Literatures, and Linguistics

340 H. B. Crouse Hall

Syracuse

New York 132441160

akahnemu@syr.edu

Diane Massam

University of Toronto

Department of Linguistics

130 St. George Street

Toronto, Ontario

M5S 3H1

diane.massam@utoronto.ca 